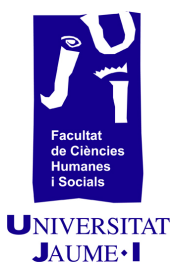

\title{
La incidencia del ajuste sobre la oralidad: el caso de la comedia negra
}

María López Rubio

marialopezrubi@hotmail.com 


\section{Resumen}

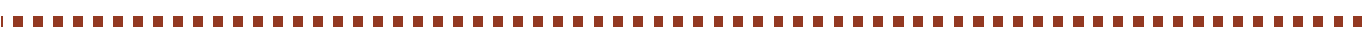

El propósito principal del presente trabajo de investigación es analizar la incidencia de la isocronía y la sincronía fonética en las soluciones de traducción para el doblaje al español de tres filmes pertenecientes al género de la comedia negra. Como punto de partida, presentamos los objetivos que se pretende alcanzar con el estudio de los ingredientes que conformarán nuestro análisis: la isocronía y la sincronía fonética y un modelo lingüístico, el dubbese o registro del doblaje, como ejemplo de discurso oral prefabricado. Seguidamente, se describe la metodología que se ha seguido para llevar a cabo el estudio. A continuación, planteamos un modelo de análisis que servirá como base para estudiar los mecanismos que se han empleado en la traducción para el doblaje al español de los primeros y primerísimos planos de la filmografía que conforma nuestro corpus, teniendo en cuenta las restricciones de la isocronía y la sincronía fonética. A partir de los datos obtenidos, tratamos de descubrir qué tendencias se siguen en la traducción para el doblaje de primeros y primerísimos planos y cómo afectan al modelo de lengua del doblaje. El resultado del análisis ha puesto de manifiesto que el traductor, el adaptador o el director de doblaje han empleado diversas estrategias y recursos que no se corresponden con el registro del doblaje descrito hasta la fecha. Por último, la comparación entre la versión original y la versión doblada al español revela que, según suponíamos, el ajuste incide notablemente en las decisiones de traducción $y$, aunque influye en la búsqueda de naturalidad de los diálogos, en muchas ocasiones se ha sorteado dicha restricción para conseguir transmitir la esencia de la comedia negra.

Palabras clave: Primeros planos, doblaje, dubbese, isocronía, sincronía fonética.

\section{Introducción}

La experiencia de consumir una obra audiovisual en versión original no es comparable a la experiencia de consumir una obra traducida. Ninguna es mejor o peor, sino que existe una diferencia lingüística. El traductor para el doblaje no se enfrenta únicamente al reto lingüístico propio de cualquier modalidad de traducción, sino que existen, además, una serie de restricciones propias del texto audiovisual que limitan las posibilidades creativas a la hora de realizar este trasvase intercultural. Mantener la ilusión cinematográfica en cualquier lengua es un objetivo equiparable al de 
conseguir la suspensión de la incredulidad, que Chaume (2012, p. 187) define como la voluntad de la audiencia de pasar por alto las limitaciones de un medio, de modo que estas no interfieran en la aceptación de las premisas que plantea el producto (mi traducción). La suspensión de la incredulidad es mucho más vulnerable en los primeros planos, pues, al tener los labios de los personajes cerca, el espectador tiende a casar con sus palabras todo lo que estos emiten a través de los diálogos. Es lo que en psicología se conoce como el efecto McGurk. Si la articulación labial no casa con el sonido que esperamos, nos sorprendemos y la ilusión cinematográfica se desvanece.

\section{Objetivos}

El principal propósito de esta investigación es analizar de manera descriptiva y cuantitativa la incidencia de la isocronía y la sincronía fonética en el doblaje al español de los primeros y primerísimos planos de tres filmes inscritos en el género de la comedia negra (Reservoir Dogs, de Quentin Tarantino; Four Rooms, de Robert Rodriguez, y Trainspotting, de Danny Boyle). mismo:

A continuación, se presentan los objetivos específicos del

- Comparar las diferencias entre diálogos originales y doblados a causa de la incidencia de la isocronía y la sincronía fonética en primeros y primerísimos planos.

- Observar qué estrategias se han llevado a cabo para traducir los diálogos en esos planos y clasificarlas partiendo del modelo lingüístico del dubbese.

- Deducir y enunciar las tendencias que existen en la traducción de dichos planos.

Evaluar, a modo de conclusiones, la incidencia del ajuste labial sobre la oralidad y observar cómo se restringen las posibilidades creativas.

\section{Material y metodología}

La metodología que se ha seguido para elaborar este trabajo es descriptiva, esto es, se han analizado y cuantificado objetivamente los datos extraídos del corpus de análisis (aunque, por razones de espacio no se han podido contrastar con datos cualitativos procedentes de entrevistas a los agentes del proceso) y se ha pretendido establecer las tendencias de traducción encontradas en el tm. Para ello, se han buscado las fuentes bibliográficas y extratextuales que contextualizan nuestro objeto de estudio, y se han estudiado los segmentos reemplazados del to $y$ los reemplazables del tm. Se trata de un estudio de caso en el que se 
analizan tres filmes doblados y sus versiones originales, de corte exploratorio - puesto que no puede ser representativo ni se ha compilado ningún catálogo general sobre cine negro-, en el que se extraen las muestras de los diálogos producidos en primeros y primerísimos planos, y se analizan cuantitativamente para observar y enunciar tendencias de traducción en los rasgos del dubbese.

En este trabajo se parte de un corpus de textos audiovisuales mediante el que se pretende analizar cómo los primeros planos exigen el cumplimiento de las sincronías, que restringen las posibilidades creativas de los traductores $y$, generalmente, obligan a presentar traducciones menos naturales (Romero Fresco, 2009). Esta figura resume el equilibrio de fuerzas de las sincronías y la oralidad en los planos que constituirán nuestro objeto de análisis:

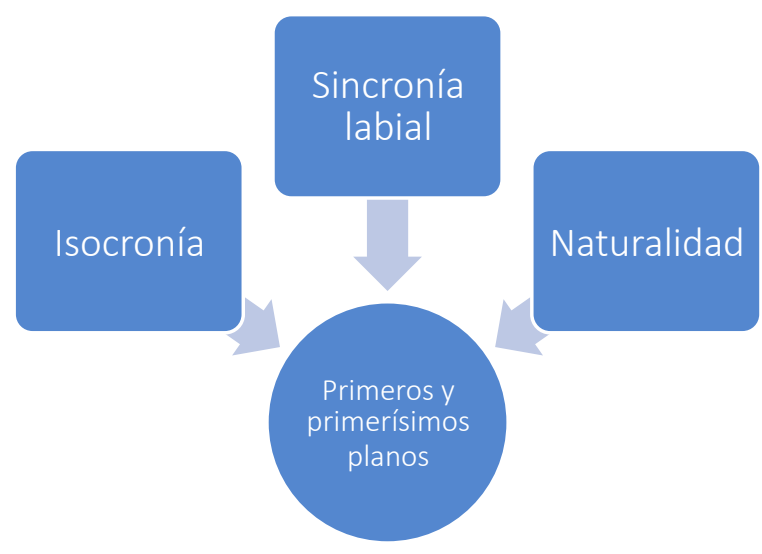

Gráfico 1. La incidencia de las sincronías y de la oralidad en la traducción de los diálogos en primeros y primerísimos planos

Para obtener resultados fiables, se han cruzado datos procedentes de las siguientes fuentes de información: bibliografía, vídeos y guiones.

\subsection{Fases del trabajo}

Para elaborar este trabajo, se han seguido los siguientes pasos:

1) Selección del tema y planteamiento de la pregunta de investigación.

2) Visionado de varios filmes correspondientes al género de la comedia negra en versión original y versión doblada al español.

3) Selección de tres de estos filmes, con criterios concretos, detección de escenas que muestran primeros y primerísimos planos (31) y transcripción de los diálogos en lengua origen y lengua meta.

4) Identificación y estudio de segmentos en los que el ajuste repercute en la traducción para el doblaje. 
5) Análisis contrastivo de los diálogos en inglés y en español e identificación mecanismos empleados en la traducción por influencia del ajuste.

6) Clasificación de los mecanismos lingüísticos detectados según el modelo del dubbese. En este punto se descubre la presencia de ciertos rasgos que no se corresponden con el modelo de análisis propuesto.

7) Estudio de los resultados y elaboración de tablas con los datos resultantes del análisis.

8) Extracción de conclusiones respecto a los resultados del análisis de la incidencia del ajuste labial en la naturalidad de los diálogos en primeros y primerísimos planos de un corpus audiovisual inscrito en el género de la comedia negra. Identificación de los mecanismos empleados para responder a las necesidades de las sincronías.

\subsection{Corpus}

Para el análisis, se han seleccionado escenas que contienen los primeros y primerísimos planos de la siguiente selección de filmes de la comedia negra, inscritos en la década de 1990-1999:

Tabla 1. Corpus de la filmografía correspondiente al género de la comedia negra

\begin{tabular}{|c|c|c|c|c|c|}
\hline Año & Título en V.O. & $\begin{array}{l}\text { Título en } \\
\text { español } \\
\text { peninsular }\end{array}$ & Director & $\begin{array}{c}\text { Estudio de } \\
\text { doblaje }\end{array}$ & $\begin{array}{c}\text { Traductor/ } \\
\text { Director }\end{array}$ \\
\hline 1992 & Reservoir dogs & Reservoir dogs & $\begin{array}{l}\text { Quentin } \\
\text { Tarantino }\end{array}$ & $\begin{array}{l}\text { International } \\
\text { Soundstudio }\end{array}$ & $\begin{array}{l}\text { Manuel Osto } \\
\text { (D) }\end{array}$ \\
\hline 1995 & $\begin{array}{l}\text { The } \\
\text { Misbehavers } \\
\text { (Four rooms) }\end{array}$ & $\begin{array}{ll}\text { Los } & \text { niños } \\
\text { malos } & \text { (Four } \\
\text { rooms) } & \end{array}$ & $\begin{array}{l}\text { Robert } \\
\text { Rodriguez }\end{array}$ & Sonoblok & $\begin{array}{lr}\text { Quico } & \text { Rovira- } \\
\text { Veleta } & \text { (T) } \\
\text { Antonio Lara } \\
\text { (D) }\end{array}$ \\
\hline 1996 & Trainspotting & Trainspotting & $\begin{array}{l}\text { Danny } \\
\text { Boyle }\end{array}$ & Cinearte & $\begin{array}{l}\text { Alfonso } \\
\text { Gallardo (D) }\end{array}$ \\
\hline
\end{tabular}

Los criterios de selección han sido los siguientes:

Este género presenta un fondo de cine negro tanto en los diálogos como en la acción y reúne elementos tomados de la comedia. Partiendo de este corpus, y de forma exploratoria, se pretende determinar de qué forma se ha lidiado con el obstáculo que supone el trasvase lingüístico para conseguir transmitir el mismo efecto en la versión doblada, y para conservar la esencia que 
caracteriza a directores como Quentin Tarantino en el tm, pese a las restricciones que supone la sincronía fonética.

- Los filmes pertenecen a una sola década para evitar que el paso del tiempo distorsione los resultados que arroje el análisis.

- Los filmes están dirigidos por tres directores diferentes, para evitar encontrarnos con rutinas del director, y para que los resultados sean lo más amplios posibles.

- Los filmes se han doblado en tres estudios distintos, para evitar que las soluciones de traducción se repitan o sean fruto de una determinada forma de actuar de un estudio.

- Los filmes han sido traducidos por traductores diferentes, para evitar también las mismas rutinas en la traducción, y observar conductas distintas.

\subsection{Ficha de análisis}

A continuación, se describe la ficha con las transcripciones de los fragmentos seleccionados que se utilizará en el análisis para comparar las versiones en original y español de las escenas seleccionadas: 
Tabla 2. Ficha-modelo de transcripción de los diálogos en primeros y primerísimos planos

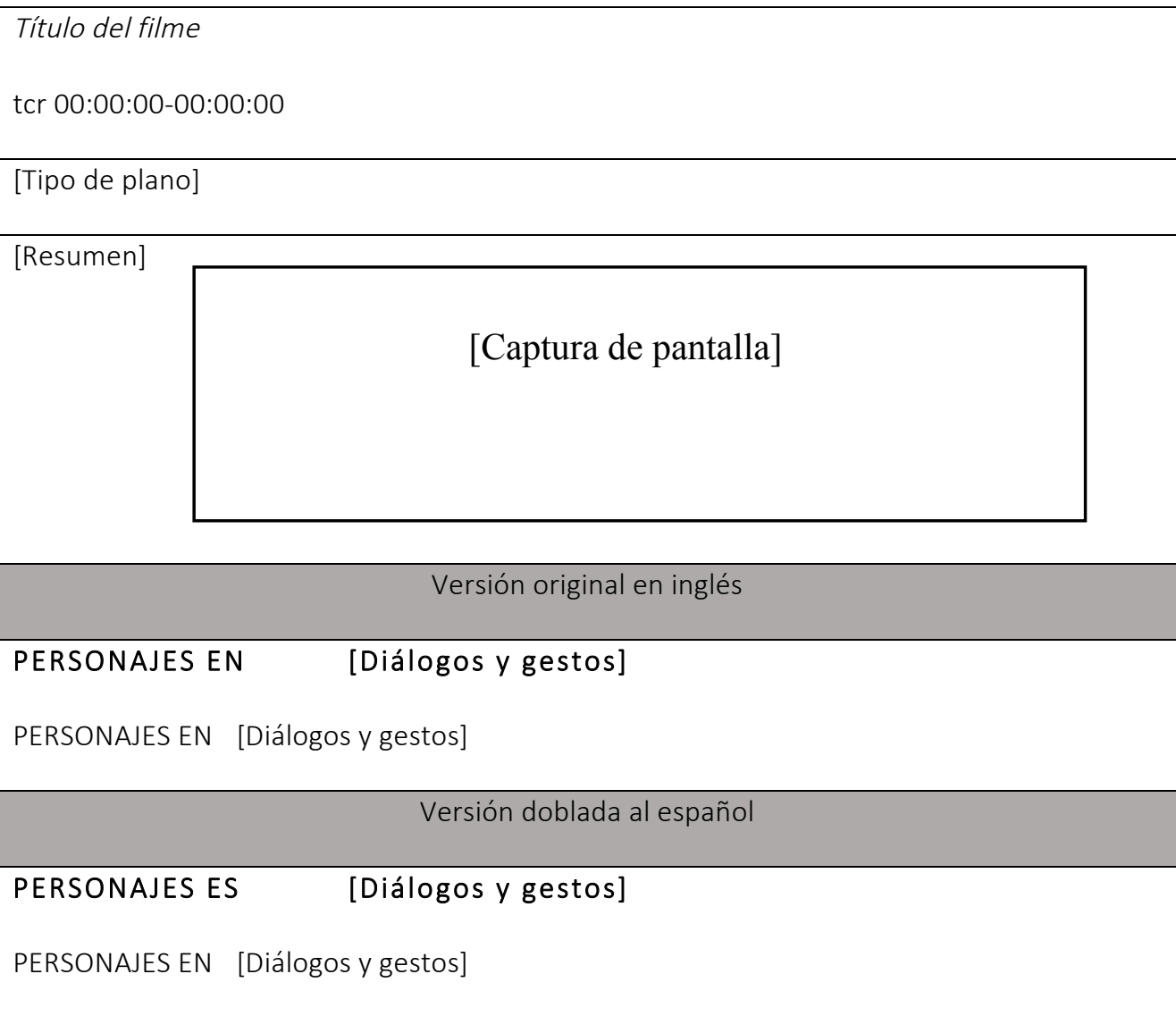




\section{Resultados}

Durante el análisis, se han estudiado los cambios producidos en un total de 31 segmentos doblados en relación con los diálogos en lengua origen. La siguiente tabla recoge las tendencias observadas respecto a la naturalidad, la isocronía y a la sincronía labial en el doblaje de los primeros y primerísimos planos:

Tabla 3. Grado de consecución de la sincronía fonética, la isocronía y la oralidad

\begin{tabular}{|c|c|}
\hline Segmentos analizados & 31 \\
\hline Segmentos en los que se ha superado la restricción de la sincronía fonética & 25 \\
\hline Segmentos en los que se ha logrado respetar la isocronía & 23 \\
\hline Segmentos en los que se aprecia oralidad en los diálogos & 28 \\
\hline
\end{tabular}

La tabla 4 desglosa el grado de cumplimiento o incumplimiento de las sincronías y de la oralidad en el análisis por segmentos de los primeros y primerísimos planos, resumido en la tabla 3.

Tabla 4. Análisis de las sincronías y de la oralidad por segmentos

\begin{tabular}{|c|c|c|c|}
\hline Segmento & Isocronía & Sincronía fonética & Oralidad \\
\hline 1 & Sí & Sí & Sí \\
\hline 2 & Sí & Sí & Sí \\
\hline 3 & Sí & Sí & Sí \\
\hline 4 & Sí & Sí & Sí \\
\hline 5 & Sí & Sí & Sí \\
\hline 6 & Sí & Sí & Sí \\
\hline 7 & Sí & Sí & No \\
\hline 8 & Sí & Sí & Sí \\
\hline 9 & Sí & No & Sí \\
\hline 10 & Sí & Sí & Sí \\
\hline 11 & Sí & Sí & Sí \\
\hline 12 & Sí & Sí & Sí \\
\hline 13 & Sí & Sí & Sí \\
\hline 14 & Sí & Sí & Sí \\
\hline 15 & No & No & No \\
\hline 16 & Sí & Sí & Sí \\
\hline 17 & Sí & Sí & Sí \\
\hline 18 & Sí & Sí & Sí \\
\hline 19 & Sí & Sí & Sí \\
\hline 20 & Sí & Sí & Sí \\
\hline 21 & No & No & No \\
\hline 22 & No & No & Sí \\
\hline 23 & No & Sí & Sí \\
\hline 24 & Sí & Sí & Sí \\
\hline 25 & No & Sí & Sí \\
\hline
\end{tabular}




\begin{tabular}{|l|c|c|c|}
\hline 26 & No & No & Sí \\
\hline 27 & Sí & Sí & Sí \\
\hline 28 & Sí & Sí & Sí \\
\hline 29 & No & Sí & Sí \\
\hline 30 & Sí & No & Sí \\
\hline 31 & No & Sí & \\
\hline
\end{tabular}

Tal y como describíamos en los primeros capítulos, nuestro principal propósito es medir la incidencia de los primeros planos sobre las posibilidades creativas en la traducción para el doblaje. Al enunciar este objetivo, partíamos de la idea de que la necesidad de mantener el mismo número de vocales abiertas y de consonantes labiales en el original y en la versión doblada obliga a presentar traducciones menos naturales, pero, como se ha observado, en 28 de los 31 segmentos analizados se aprecia la oralidad en los diálogos pese a la restricción que supone el ajuste en el doblaje. Son casos en los que no solo se ha mantenido la esencia del original, sino que, además, se han vencido las restricciones propias del doblaje sin incurrir en traducciones literales y poco creíbles (Whitman, 1992; Gautier, 1981). Para ello, se han empleado recursos lingüísticos que en muchos casos coinciden con el modelo del dubbese, pero que en otros pertenecen a un modelo distinto.

A diferencia de lo que podría deducirse, el número de segmentos en los que se ha perdido naturalidad en los diálogos por exigencias de la sincronía fonética es muy reducido. Solo en 4 de los 31 segmentos se aprecia este fenómeno. De hecho, en los segmentos analizados hay más pérdidas de isocronía (8) y de sincronía fonética (6), que de naturalidad (3). Generalmente, para contrarrestar los casos en los que el doblaje se ha visto forzado a incluir mecanismos que restan naturalidad a los diálogos, se emplean técnicas de compensación, tales como el uso de términos malsonantes, que no resultan ajenos a la comedia negra.

Los datos del siguiente gráfico constatan estas observaciones:

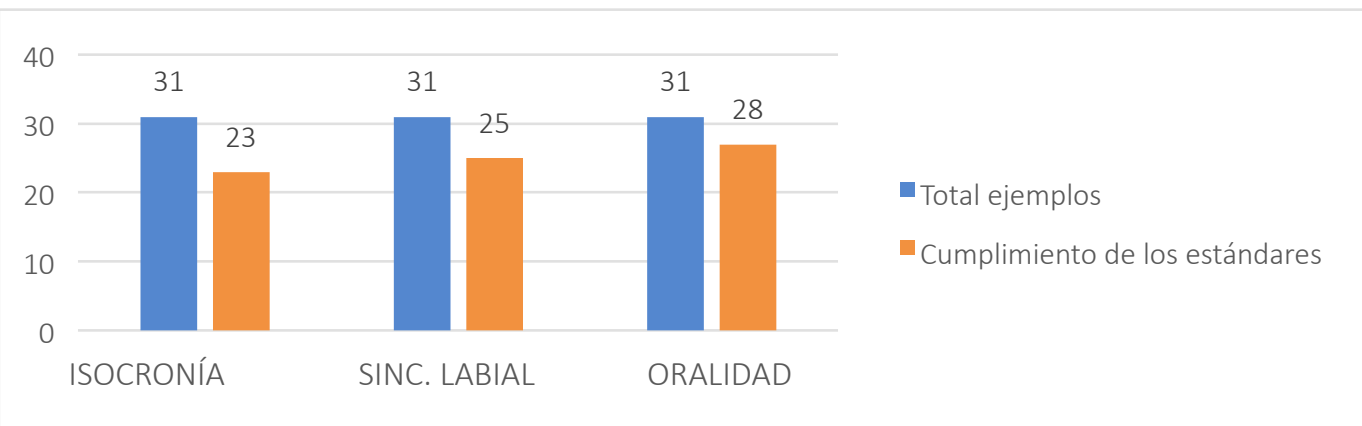

Gráfico 2. Datos relativos al mantenimiento de las sincronías y la oralidad en 31 
Como se muestra en el gráfico, la isocronía se ha logrado mantener en 23 de los 31 segmentos que analizamos, esto es, en un $74,19 \%$. La sincronía fonética se ha respetado en 25 de los 31 segmentos, es decir, en el $80,65 \%$ de los casos. La oralidad de los diálogos, que se refleja en 28 de los 31 segmentos, representa el $90,32 \%$.

Según los datos que arrojan los segmentos analizados, se han empleado un total de 109 mecanismos lingüísticos en la traducción para el doblaje de los primeros y primerísimos planos, entre los que destacan rasgos propios del dubbese y otros mecanismos que no pertenecen a este modelo, pero que también inciden en la recepción los diálogos doblados.

Tabla 5. Clasificación de los mecanismos observados según el modelo que analizamos u otros procedimientos

\begin{tabular}{|l|c|}
\hline Segmentos analizados & 31 \\
\hline Mecanismos observados & 120 \\
\hline Mecanismos correspondientes al dubbese & 89 \\
\hline Otros procedimientos & 31 \\
\hline
\end{tabular}

Tal y como recoge la tabla 5 , más de la mitad de los mecanismos se corresponden con el modelo del dubbese. En las siguientes tablas pueden apreciarse los diferentes mecanismos encontrados en la traducción para el doblaje de los tres filmes seleccionados para el corpus. En la tabla 6 se muestran los rasgos específicos del dubbese que se han detectado tras analizar los 31 segmentos; mientras que la tabla 7 está formada por aquellos mecanismos que no se corresponden con los rasgos específicos del dubbese descritos hasta la fecha.

Tabla 6. Mecanismos pertenecientes al registro del doblaje

\begin{tabular}{|c|c|c|c|}
\hline $\begin{array}{c}\text { Rasgos específicos } \\
\begin{array}{c}\text { Rocativos y } \\
\text { exclamaciones }\end{array}\end{array}$ & Empleo & Nivel lingüístico \\
\hline $\begin{array}{c}\text { Expresividad y } \\
\text { creatividad léxica } \\
\text { estructuras sintácticas } \\
\text { del registro coloquial }\end{array}$ & $\begin{array}{c}\text { Expresividad y } \\
\text { creatividad léxica }\end{array}$ & 4 & Léxico-semántico \\
\hline $\begin{array}{c}\text { Uso de neologismos } \\
\text { formales }\end{array}$ & Creación léxica & 1 & Léxico-semántico \\
\hline $\begin{array}{c}\text { Uso de términos } \\
\text { vulgares }\end{array}$ & Tacos y términos vulgares & 10 & Léxico-semántico \\
\hline
\end{tabular}




\begin{tabular}{|c|c|c|c|}
\hline $\begin{array}{c}\text { Uso de estructuras } \\
\text { sintácticas breves y } \\
\text { sencillas }\end{array}$ & Organización textual & 2 & Sintáctico \\
\hline $\begin{array}{c}\text { Uso de expresiones de } \\
\text { apertura y cierre del } \\
\text { discurso oral }\end{array}$ & Unión entre enunciados & 9 & Sintáctico \\
\hline $\begin{array}{l}\text { Uso de la deixis personal } \\
\text { (yo/tú) }\end{array}$ & Referencias exofóricas & 4 & Sintáctico \\
\hline Realce de elementos & Organización textual & 5 & Sintáctico \\
\hline $\begin{array}{l}\text { Evitación de estructuras } \\
\text { pasivas }\end{array}$ & Estructuras pasivas & 1 & Sintáctico \\
\hline $\begin{array}{l}\text { Elipsis de elementos de } \\
\text { la oración }\end{array}$ & Elipsis & 14 & Sintáctico \\
\hline Repeticiones y adiciones & Grado de redundancia & 9 & Sintáctico \\
\hline $\begin{array}{l}\text { Evitación de la } \\
\text { discontinuidad }\end{array}$ & Organización textual & 2 & Sintáctico \\
\hline $\begin{array}{c}\text { Evitación de préstamos } \\
\text { externos }\end{array}$ & Creación léxica & 3 & Léxico-semántico \\
\hline $\begin{array}{l}\text { Uso de genéricos y } \\
\text { comodines }\end{array}$ & Selección léxica & 1 & Léxico-semántico \\
\hline $\begin{array}{l}\text { Uso de palabras de rasgo } \\
\text { más coloquial, si las } \\
\text { comparamos con otras } \\
\text { más formales }\end{array}$ & Selección léxica & 3 & Léxico-semántico \\
\hline $\begin{array}{l}\text { Uso de elementos } \\
\text { enfáticos }\end{array}$ & Organización textual & 6 & Sintáctico \\
\hline
\end{tabular}

Respecto a los mecanismos del modelo de lengua del dubbese, la siguiente tabla clasifica las principales tendencias aplicadas al doblaje de los primeros y primerísimos planos: 


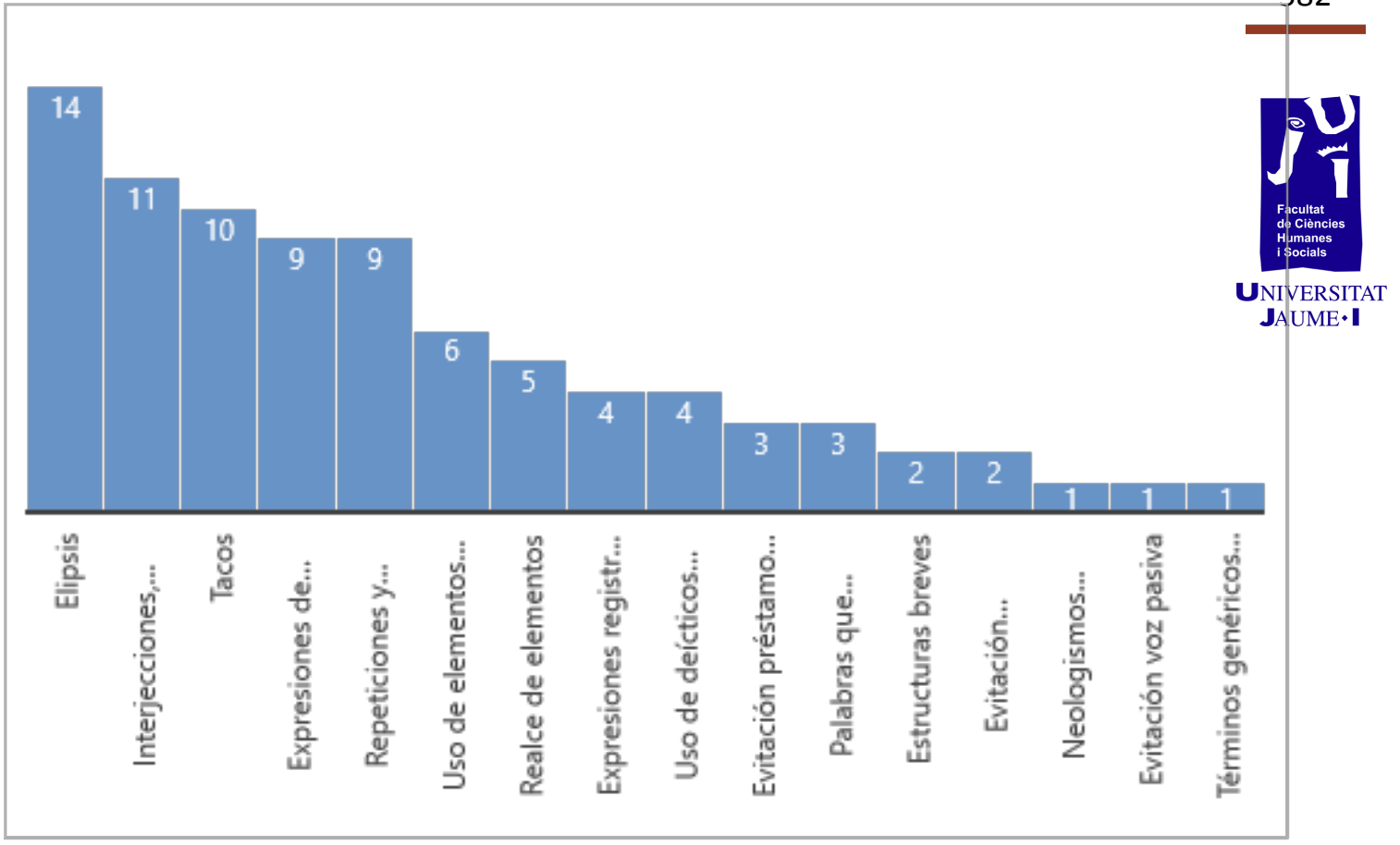

Gráfico 3. Rasgos del registro del doblaje que son tendencia en los primeros y primerísimos planos

A simple vista puede apreciarse que en los textos seleccionados para el corpus se emplean tres mecanismos especialmente recurrentes. Con un total de 14 coincidencias destaca la elipsis, que es común en el doblaje por necesidades de isocronía. El segundo rasgo de la lista (con 11 casos) es el empleo de interjecciones, vocativos y exclamaciones. A esta característica le sigue otra que es propia del dubbese: el uso de términos vulgares, con 10 casos.

Aunque pudiera parecer contradictorio, en ciertos casos se ha elidido el término malsonante en la versión doblada porque el uso de algunas expresiones como "fucking» no habría resultado natural en el tm. En la medida de lo posible, se ha tratado de mantener los términos malsonantes en lengua meta para conservar la esencia del género, pero, cuando no ha sido posible, se ha empleado la compensación. A continuación, encontramos tendencias que confieren un tono conversacional y muy fluido al discurso doblado, tales como el uso de expresiones o estructuras sintácticas propias del registro coloquial, el uso de expresiones de apertura y cierre propias del discurso oral y el empleo de adiciones y repeticiones.

Seguidamente, abordamos una de las cuestiones que mayor interés suscita en el marco del presente trabajo. Se trata de los mecanismos detectados a lo largo de los segmentos del corpus que no se corresponden con el modelo de lengua del dubbese en español (aunque algunos sí en catalán, Marzà, 2016) Una vez etiquetados, observamos que el uso de ciertos de ellos es bastante recurrente a lo largo de todo el análisis. Pese a que no existe un estudio empírico en 
el que poder sustentarnos, estos rasgos específicos tienen implicaciones evidentes en la recepción de los diálogos que hemos indicado de forma meramente orientativa en la siguiente tabla.

Tabla 7. Mecanismos que no se corresponden con el registro del doblaje

\begin{tabular}{|c|c|c|}
\hline Mecanismos & Empleo & Implicaciones \\
\hline Cambio de la modalidad oracional & 2 & Naturalidad \\
\hline Estructuras con «lo» neutro & 4 & Naturalidad \\
\hline Términos propios del doblaje & 2 & Artificialidad \\
\hline $\begin{array}{l}\text { Anteposición y posposición de } \\
\text { adjetivos }\end{array}$ & 2 & Naturalidad \\
\hline Transposición & 3 & Naturalidad \\
\hline $\begin{array}{l}\text { Supresión del posesivo cuando no } \\
\text { indica una pertenencia real }\end{array}$ & 2 & Naturalidad \\
\hline Uso de digresiones o paráfrasis & 3 & Naturalidad \\
\hline $\begin{array}{l}\text { Empleo del posesivo cuando no indica } \\
\text { una pertenencia real }\end{array}$ & 1 & Artificialidad \\
\hline $\begin{array}{l}\text { Empleo de adverbios acabados en - } \\
\text { mente }\end{array}$ & 2 & Artificialidad \\
\hline $\begin{array}{l}\text { Empleo del determinante demostrativo } \\
\text { «este» con valor despectivo }\end{array}$ & 2 & Naturalidad \\
\hline Inconsistencia de tiempos verbales & 1 & Naturalidad \\
\hline $\begin{array}{c}\text { Empleo del artículo indeterminado } \\
\text { propio del inglés }\end{array}$ & 1 & Artificialidad \\
\hline Uso de la deixis personal (yo/tú) & 14 & Naturalidad/artificialidad \\
\hline
\end{tabular}

Respecto a los mecanismos que no coinciden con el dubbese, en la tabla que se presenta a continuación se muestran las principales tendencias aplicadas a la traducción de los primeros y primerísimos planos: 


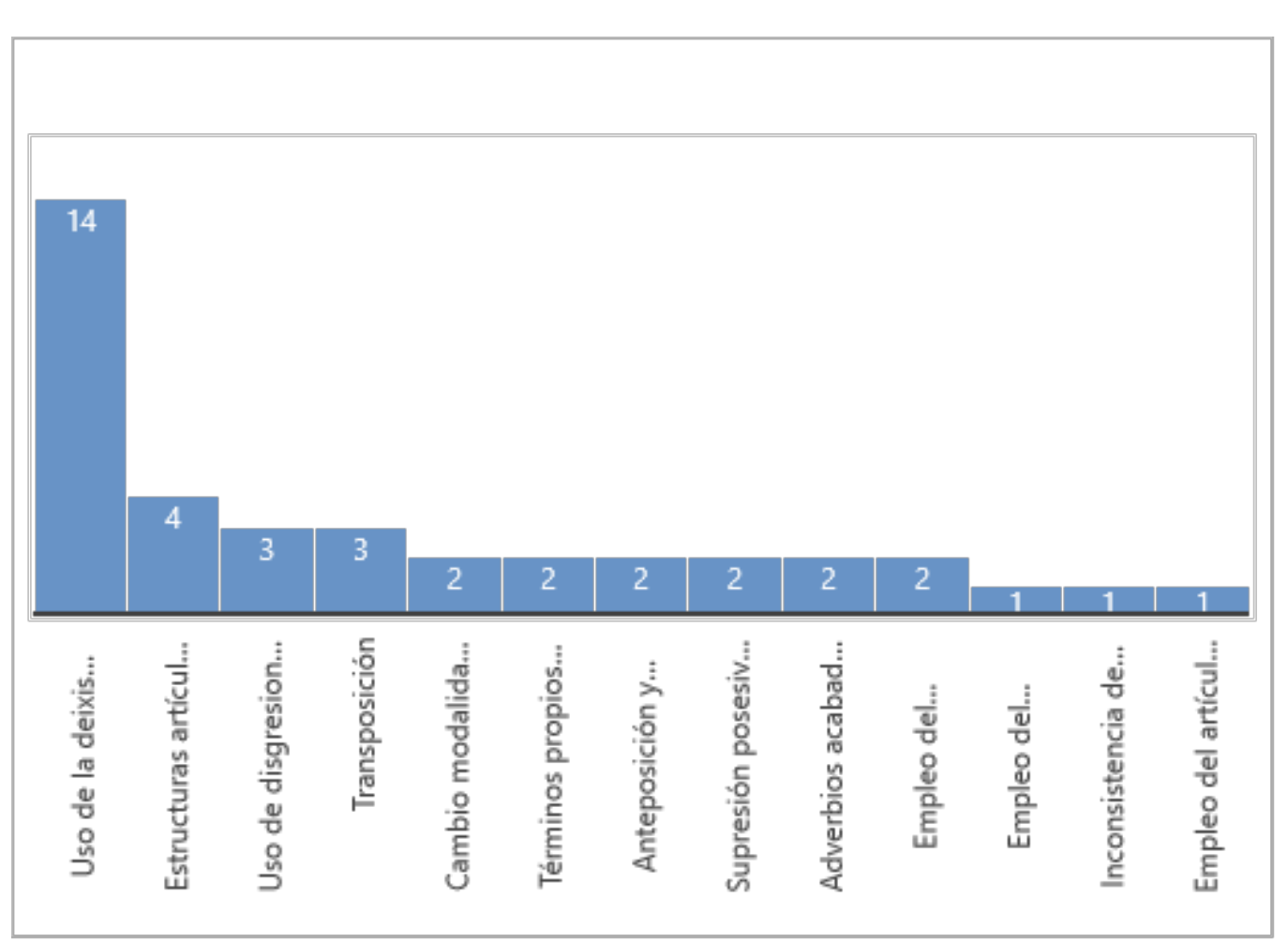

Gráfico 4. Mecanismos que no se corresponden con el registro del doblaje

Entre los rasgos principales de este segundo modelo de lengua destaca el uso de la deixis personal (yo/tú), con 14 coincidencias. El empleo de este mecanismo responde, en la mayoría de los casos, a razones de isocronía. En ocasiones su uso ha supuesto una notable pérdida de oralidad, mientras que en otros casos su empleo cumple una función intensificadora que confiere naturalidad al discurso doblado. Con menor presencia, le siguen el uso estructuras formadas por el artículo neutro «lo», la transposición y el desplazamiento de información. Los demás rasgos son menos recurrentes, pero repercuten de igual modo en la oralidad.

\section{Discusión y conclusiones}

Dentro de las posibilidades de este estudio, se ha tratado de determinar los principales mecanismos de la traducción para el doblaje, los modelos de lengua en los que se inscriben y la incidencia que tienen en los diálogos, si cumplen con las exigencias de la sincronía fonética y refuerzan la naturalidad del producto meta, o si algún estándar de calidad se ve afectado por la necesidad de cumplir con la otra convención. Resulta interesante analizar el esfuerzo por mantener la esencia del género a través de mecanismos que distan de la traducción literal.

Pese a que el ajuste labial supone una restricción para el doblaje, observamos soluciones creativas que respetan la sincronía fonética. Detectamos rasgos indicadores del dubbese y otros mecanismos que 
no se corresponden con el registro del doblaje. También se detectan usos no habituales del español oral espontáneo, como el uso incorrecto del posesivo cuando no se indica posesión como tal por exigencias del ajuste. Aunque en ocasiones el ajuste labial ha puesto trabas a la hora de conseguir diálogos naturales, las proyecciones en lengua meta constituyen un cúmulo de equilibrios entre un estándar de calidad y otro, por lo que el texto cumple con las expectativas del polo receptor. Finalmente, se confirma la hipótesis de que en la traducción diálogos en estos planos tienen prioridad las sincronías y la oralidad sobre la equivalencia. Los hallazgos más sobresalientes han sido la comprobación de los equilibrios mencionados, el alto grado de cumplimiento de las sincronías y de la naturalidad en los diálogos, el hecho de que esta naturalidad ha primado sobre el cumplimiento de las sincronías y los nuevos rasgos detectados, no descritos en el dubbese, aspectos que habrá que comprobar en un corpus mayor.

\section{Bibliografía}

Bender, Lawrence (productor) y Quentin Tarantino (director). 1992. Reservoir dogs. Estados Unidos. Live Entertainment: Dog Eat Dog Productions Inc.

Bender, Lawrence (productor) y Robert Rodriguez (director). 1995. Four rooms. The Misbehavers. Estados Unidos: A Band Apart.

Chaume Varela, Frederic. 2012. Audiovisual Translation: Dubbing. Londres: Routledge.

Gautier, Gérard-Louis. 1981. "La traduction au cinema: nécessité et trahison». La revue du cinéma 363: 101-118.

Marzà Ibàñez, Anna. 2006. La naturalitat en la traducció per al doblatge. El cas dels marcadors d'intensificació. Tesis doctoral. Castelló de la Plana: Universitat Jaume I. Accés http://www.tdx.cat/bitstream/handle/10803/398396/2016_Tesi s_Marza\%20lba\%C3\%B1ez_Anna.pdf?sequence=1\&isAllowed=y

Macdonald, Andrew y Christopher Figg (productores) y Danny Boyle (director). 1996. Trainspotting. Reino Unido: Film4 Productions.

Romero Fresco, Pablo. 2009. "Naturalness in the Spanish Dubbing Language: a Case of Not-so-close Friends 1». Meta 54 (1): 49-72 . Acceso

https://www.erudit.org/revue/meta/2009/v54/n1/029793ar.pdf

Whitman-Linsen, Candace. 1992. Through the Dubbing Glass. Fráncfort del Meno: Peter Lang. 